\title{
MENINGKATKAN KOMPETENSI KETERAMPILAN GERAK DASAR LOKOMOTOR MELALUI PERMAINAN OUTDOOR
}

\author{
Rafat Wahidin ${ }^{(1)}$ Sunardi $^{(2)}$

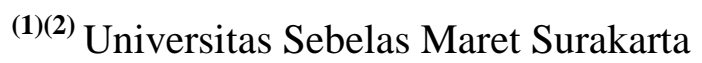

\begin{abstract}
Penelitian ini bertujuan untuk meningkatan kompetensi keterampilan gerak dasar lokomotor melalui permainan outdoor. Penelitian ini dilakukan di SD Negeri Danaraja Banyumas pada tahun ajaran 2016/2017.

Subyek penelitian adalah siswa kelas II berjumlah 26 siswa dan obyek penelitinnya adalah meningkatkan kompetensi keterampilan gerak dasar lokomotor melalui permainan outdoor. Jenis penelitian adalah penelitian tindakan kelas (PTK) yang bersifat kolaboratif antara peneliti bekerjasama dengan guru penjasorkes. Penelitian ini dilakukan dalam dua siklus terdiri dari 6 kali pertemuan, kemudian tahap dalam setiap siklusnya yang terdiri dari perencanaan, pelaksanaan tindakan, observasi dan refleksi. Teknik pengumpulan data meliputi observasi, tes dan refleksi. Teknik analisis data dalam penelitian ini adalah menelaah semua data yang tersedia, baik data kuantitatif secara statistik deskriptif komparatif (persentase) maupun data kualitatif secara analisis kritis.

Berdasarkan hasil penelitian disimpulkan bahwa pembelajaran melalui permainan outdoor dapat meningkatkan kompetensi keterampilan gerak dasar lokomotor yang semula pada prasiklus kelulusan sebesar 34,6\% menjadi 61,5\% pada siklus I, dan pada siklus II meningkat menjadi 76,9\%, sehingga kompetensi mengalami peningkatan sebesar $42,3 \%$.
\end{abstract}

Kata kunci : Permainan Outdoor, Keterampilan Gerak Dasar Lokomotor 


\section{PENDAHULUAN}

Keterampilan gerak dasar adalah bentuk gerakan-gerakan sederhana yang dibagi ke dalam tiga gerak yaitu keterampilan gerak dasar lokomotor (gerakan memindahkan tubuh dari satu tempat ke tempat lain: berlari, berjalan, melompat, dll), gerak non lokomotor (gerakan dilakukan di tempat tanpa ada ruang memadai: menekuk, meregangkan, mendorong, menarik, dll), gerak manipulatif (gerakan yang dikembangkan ketika masa kanakkanak. Dalam silabus pembelajaran Penjasorkes, salah satu materi yang harus diajarkan adalah keterampilan gerak dasar lokomotor. Keterampilan gerak dasar lokomotor adalah kemampuan untuk melakukan gerakan anggota tubuh untuk membuat seluruh tubuh berpindah tempat. Adapun macam keterampilan yang termasuk dalam keterampilan gerak dasar lokomotor meliputi: run (lari), hop (engklek), leap (berjingkrak/melangkah jauh ke depan), Horizontal Jump (melompat ke depan), Gallop (mencongklang), dan Slide (menyelusur / mencongklang ke samping).

Masalah penting dalam Penjasorkes yang diterapkan di SD Negeri Danaraja Banyumas adalah belum efektifnya pengajaran, juga rendahnya kualitas pembelajaran yang dilakukan di sekolah tersebut. Hal ini disebabkan oleh beberapa faktor yang diantaranya adalah kurang maksimalnya pembelajaran Penjasorkes dan terbatasnya sumbersumber dan media atau alat bantu yang digunakan untuk bahan mengajar. Model pembelajaran yang diterapkan saat mengajar masih condong bersifat konvensional dimana sering terjadi siswa hanya diperintahkan untuk jalan-jalan/lari di kampung dekat sekolah kemudian kembali ke sekolah, contoh lainnya siswa hanya diberi alat seperti misalnya bola untuk dimainkan tanpa ada sebuah rancangan atau model atau strategi pembelajaran yang lebih baik. Atau kalau tidak demikian, maka hanya pemberian tugas dalam kelas atau semacam ruang kosong bebas tidak terpakai. Dengan pembelajaran yang dilakukan dalam 
kelas ini mengakibatkan ruang gerak siswa terbatas. Karena ukuran kelas yang sempit dengan banyaknya siswa kelas 2 yang sebanyak 26 anak, maka ketika siswa melakukan aktifitas gerak udara dalam kelas tersebut menjadi pengap dan kurang mendukung siswa untuk bernafas bebas untuk melakukan gerak.

Hasil observasi di SD Negeri

Danaraja Banyumas menunjukkan bahwa siswa-siswi kelas II SD tersebut saat berolahraga melakukan gerak dasar yang kurang baik, selain itu para siswa juga sering mengeluh bosan dan kurang antusias karena pelajaran yang diberikan monoton dan kurang menarik sehingga siswa kurang memperhatikan, serta siswa berbicaradan bermain sendiri dengan teman lain saat proses pembelajaran, hal ini menyebabkan ketidakmampuan siswa ketika mempraktikkan gerakan.

Untuk mengatasi masalah yang ada di kelas tersebut maka pembelajaran disampaikan melalui permainan(khususnya permainan outdoor). Melalui aktivitas bermain, sangatlah tepat untuk mengembangkan keterampilan gerak dasar anak di sekolah dasar, karena pada dasarnya dunia anak-anak adalah dunia bermain.

Jenis-jenis permainan diantaranya adalah permainan tradisional dan modern, permainan berbahaya dan aman, permainan mental dan fisik, permainan alamiah dan diorganisir, permainan indoor dan outdoor, permainan aktif dan pasif, dan lain- lain. Mengacu pada buku Developing Fundamental Movement Skills Teachers' Guide Foundation Stage Physical Development, FMS dapat dan harus diperkuat/ditingkatkan melalui: (1) Guru memimpin kegiatan, (2) Anak yang dipimpin kegiatan, (3) Belajar melalui bermain, termasuk bermain di luar(outdoor play), (4) kegiatan di tempat bermain, (5) Kegiatan di rumah dan (6) lingkungan sosial. Ini menunjukkan bahwa kompetensi keterampilan gerak dasar yang didalamnya termasuk ketrampilan gerak dasar lokomotor dapat ditingkatkan melalui permainan outdoor. Dengan bermain diluar ruangan anak akan merasa lebih bebas mengekpresikan dirinya karena memiliki ruang gerak yang 
luas dan suasana berbeda dalam aspek kognitif atau tingkat dibandingkan dalam ruangan. penguasaan materi pembelajaran Permainan outdoor memberi ruang gerak yang amat bebas, dan secara bersamaan dapat meningkatkan perkembangan fisik anak secara total dan optimal.

\section{METODE}

Penelitian Tindakan Kelas (PTK) ini dilaksanakan pada bulan September sampai dengan Oktober 2016. Kegiatan penelitian dilaksanakan sesuai dengan jadwal pelajaran Penjasorkes kelas II SD Negeri Danaraja Banyumas. Subjek dalam penelitian ini adalah siswa kelas II SD Negeri Danaraja Banyumas Tahun Pelajaran 2016/2017 yang berjumlah 26 siswa terrdiri dari 12 laki-laki dan 14 perempuan. Data yang digunakan dalam Penelitian ini adalah data primer dan data sekunder. Sumber data diperoleh dari Guru dan Siswa. Teknik pengumpulan data dalam Penelitian Tindakan Kelas (PTK) ini terdiri atas tes, observasi dan dokumentasi. Tes dipergunakan sebagai teknik pengumpulan data untuk mengukur kemampuan siswa

keterampilan gerak dasar lokomotor. Observasi dipergunakan sebagai teknik untuk mengumpulkan data tentang kompetensi keterampilan gerak dasar lokomotor siswa dan tentang aktivitas siswa selama mengikuti proses belajar mengajar keterampilan gerak dasar lokomotor melalui permainan outdoor. Dokumentasi yang digunakan untuk memperoleh data sekolah dan identitas anak, antara lain seperti nama, nomor induk, tempat tanggal lahir anak dengan melihat dokumentasi yang ada dalam sekolah. Dokumentasi juga berupa foto rekaman proses tindakan, yaitu foto rekaman proses pembelajaran kompetensi keterampilan gerak dasar lokomotor melalui permainan outdoor.

\section{HASIL DAN PEMBAHASAN}

Berdasarkan hasil data awal sebelum diberikan tindakan, maka dapat dijelaskan Ketuntasan yang diperoleh siswa kelas II SD Negeri Danaraja Banyumas hanya 34,6 \% saja setara dengan 9 siswa, sehingga 
masih 17 siswa yang belum bisa menguasai materi keterampilan gerak dasar lokomotor sesuai dengan Kriteria Ketuntasan Minimal(KKM).

Melalui deskripsi data awal yang telah diperoleh tersebut menunjukkan tingkat keberhasilan pembelajaran yang belum sesuai harapan. Maka disusun sebuah tindakan untuk meningkatkan kompetensi keterampilan gerak dasar lokomotor siswa kelas II SD Negeri Danaraja Banyumas, yaitu melalui permainan outdoor. Pelaksanaan tindakan dilakukan sebanyak 2 siklus, yaitu masing-masing siklus terdiri atas 4 tahapan, yaitu: (1) Perencanaan, (2) Pelaksanaan Tindakan, (3) Observasi, (4) Refleksi.

\section{SIKLUS I}

Ketika pelaksanaan tindakan I, peneliti bersama guru penjasorkes melakukan penilaian terhadap proses pembelajaran siswa yang digunakan sebagai data penelitian. Deskripsi data yang di ambil oleh peneliti adalah tes unjuk kerja / tes praktik menggunakan tes TGMD-2 siswa kelas II SD Negeri Danaraja Banyumas tahun ajaran 2016/2017. Kompetensi keterampilan gerak dasar lokomotor setelah diberi tindakan I yaitu melalui permainan outdoor. Proses pembelajaran siswa seselesainya pemberian tindakan I menunjukan bahwa hasil yang didapat belum sesuai dengan harapan yaitu $70 \%$ setara dengan 18 siswa dari 26 siswa, sedangkan hasil yang di dapat siswa baru $61,5 \%$ atau 16 siswa dari 26 siswa.

Berdasarkan hasil refleksi yang dilakukan pada akhir pembelajaran siklus I diketahui bahwa masih terdapat kekurangan dari target yang ditentukan, maka pembelajaran akan direvisi dan dilakukan revisi perencanaan, pelaksanaan revisi perencanaan, observasi pelaksanaan revisi perencanaan, evaluasi dari hasil pelaksanaan revisi perencanaan, dan refleksi dari revisi perencanaan. Kegiatan ini dilaksanakan agar capaian dari kompetensi keterampilan gerak dasar lokomotor dapat sesuai dengan target yang disepakati, sehingga pembelajaran dilanjutkan pada siklus berikutnya. 
SIKLUS II

Pada siklus II yang merupakan tindak lanjut dan perbaikan formula dari hasil analisis dan refleksi pada siklus I, yang mana pada siklus I diketahui bahwa kompetensi mengalami peningkatan akan tetapi masih belum mencapai target yang di targetkan.

Dalam rencana pelaksanaan tindakan siklus II tidak jauh beda dengan pelaksanaan tindakan siklus I, hanya saja dalam siklus II diberikan trik-trik untuk menanggulangi kesalahan yang sama saat dilakukannya tindakan pada siklus I.

Selama pelaksanaan treatment II peneliti bersama kolaborator melakukan pengambilan data, adapun data yang di ambil kompetensi keterampilan gerak dasar lokomotor menggunakan tes TGMD-2 untuk kelas II SD Negeri III Danaraja Banyumas tahun ajaran 2016/2017.

Berikut akan dipaparkan kompetensi keterampilan gerak dasar lokomotor siswa kelas II SD Negeri III Danaraja Banyumas tahun ajaran 2016/2017 pasca pemberian treatment II,
Pembelajaran melalui permainan outdoor meningkatkan ruang gerak dan membuat semua siswa nampak aktif dan antusias mengikuti pembelajaran. Kegiatan tersebut menjadikan pembelajaran yang dilakukan pada siklus II menjadi efektif dan tujuan pembelajaran dapat tercapai. Persentase kelulusan kompetensi keterampilan gerak dasar lokomotor siswa meningkat menjadi $76,9 \%$.

\section{PERBANDINGAN ANTAR}

\section{SIKLUS}

Perbandingan kompetensi keterampilan gerak dasar lokomotor Siswa kelas II SD Negeri Danaraja Banyumas tahun ajaran 2016/2017 pada akhir siklus I dan II yaitu:

1. Ketuntasan pada prasiklus sebanyak 9 siswa. Pada siklus I sebanyak 16 siswa dan meningkat pada siklus II menjadi 20 siswa yang mencapai kelulusan.

2. Dalam prosentase dapat disajikan dengan data ketuntasan prasikluas sebanyak 34,6\%, siklus I sebanyak $61,5 \%$ dan meningkat pada siklus II menjadi $76,9 \%$. 
SIMPULAN, IMPLIKASI DAN

\section{SARAN}

\section{SIMPULAN}

Penelitian tindakan kelas pada siswa kelas II SD Negeri Danaraja Banyumas dilaksanakan dalam dua siklus. Setiap siklus terdiri dari empat tahap. Berdasarkan data yang telah dituangkan pada BAB IV dapat diperoleh kesimpulan bahwa, pembelajaran melalui permainan outdoor dapat meningkatkan kompetensi keterampilan gerak dasar lokomotor siswa kelas II SD Negeri Danaraja tahun ajaran 2016/2017. Dari hasil analisis yang diperoleh peningkatan yang terjadi dari data awal/prasiklus sampai ke siklus I adalah ditunjukan dalam persentase $34,6 \%$ (9 siswa) menjadi 61,5\% (16 siswa). Dan dari siklus I ke siklus II adalah dari persentase $61,5 \%$ (16 siswa) menjadi 76,9\% (20 siswa).

\section{IMPLIKASI}

1. Berdasarkan simpulan peneliti yang telah di kemukakan di atas, maka dapat dipahami bahwa pembelajaran melalui permainan outdoor dapat meningkatkan kompetensi keterampilan gerak dasar lokomotor adalah menjadi cara yang efektif untuk meningkatkan kompetensi keterampilan gerak dasar lokomotor. Dengan demikian, implikasi penelitian tindakan kelas ini adalah:

2. Penelitian ini memberikan cerminan bahwasannya keberhasilan meningkatkan kompetensi keterampilan gerak dasar lokomotor terdiri dari beberapa komponen penyusunnya dan dari komponen-komponen pembelajaran itu keberhasilan tujuan pembelajaran dapat tercapai. Komponen tersebut adalah guru, siswa, kurikulum, dan intruksi. Guru mempunyai peran untuk mengembangkan silabus dan membuat RPP, menyuguhkan gaya mengajar yang inovatif, menunjukan kepribadian yang karismatik, memanagement kelas, waktu, dan materi pembelajaran dengan baik, serta menguasai trik-trik, teknikteknik, metode-metode dan mempunyai banyak tip agar pembelajaran dapat optimal. 
Siswa memiliki gaya belajar yang berbeda-beda dan masing-masing adalah unik, maksudnya tidak dapat disamakan satu dengan yang lainnya. Kemampuan siswa untuk menyemangati diri mereka sendiri, memotivasi diri mengelola kepercayaan diri juga berdeda-beda. Kurikulum yang dibuat oleh pemerintah selalu mengalami perbaikan dengan tujuan pembelajaran nasional semakin hari semakin maju. Kurikulum, silabus, program tahunan, program semesteran dan lain-lain dibuat untuk memudahkan guru dalam proses pembuatan program pembelajaran. Intruksi dalam rangka pelaksanaan pembelajaran meliputi pendekatan, metode, model pembelajaran disuguhkan dalam jenis yang bermacamacam.

3. Memberikan deskripsi yang jelas bahwa dengan penerapan pembelajaran melalui permainan outdoor dapat meningkatkan kompetensi keterampilan gerak dasar lokomotor siswa, sehingga penelitian ini dapat digunakan sebagai suatu pertimbangan bagi guru penjasorkes yang berkeinginan untuk menggunakan pembelajaran melalui permainan outdoor dapat meningkatkan kompetensi keterampilan gerak dasar lokomotor.

4. Penerapan pembelajaran melalui permainan outdoor dapat meningkatkan kompetensi keterampilan gerak dasar lokomotor, sehingga siswa dapat mengeksplorasi diri mereka dan belajar sesuai dengan gaya mereka masing-masing dengan tetap memenuhi tujuan pembelajaran.

5. Penerapan pembelajaran melalui permainan outdoor dapat meningkatkan kompetensi keterampilan gerak dasar lokomotor. Setelah pendekatan pembelajaran melalui permainan outdoor diterapkan hampir tidak nampak siswa duduk-duduk di pinggir lapangan atau mencari tempat yang teduh, semua siswa nampak aktif dan antusias mengikuti pembelajaran dikarenakan memang 
pembelajaran melalui permainan

outdoor belum pernah

dipraktikan oleh guru penjas

disaat mengajar mengajar

sebelumnya. Secara umum

pembelajaran dapat dikategorikan

berhasil.

\section{SARAN}

Setelah melakukan penelitian penulis menyampaikan saran pada:

1. Guru panjasorkes agar:

a. Berupaya untuk meningkatkan

kompetensi keterampilan gerak dasar lokomotor melalui permainan outdoor.

b. Pada pembelajaran melalui permainan outdoor dapat meningkatkan

kompetensi keterampilan gerak dasar lokomotor, dapat menerapkan permainan:

a) Satu sate

b) Robot pencari harta karun c) Mengambill harta karun

d) Kuda mengambbil rumput

e) Kuda dan singa

f) Mengusir bango

g) Lari 3 kaki

h) Sunda manda/ engklek

i) Menyebrang dengan kertas

j) Menjaring katak

k) Lomba kanguru

1) Gobag sodor

m) Sebenarnya kebalikan

n) Bango mematuk katak

o) Menghindari kepiting

p) Melewati kotak

c. Pembelajaran melalui permainan outdoor membuat rasa penasaran memuncak sehingga siswa akan antusias dalam proses pembelajaran gerak dasar lokomotor dengan demikian kegiatan belajar mengajar dapat menjadi kondusif.

d. Membiasakan dengan penilaian TGMD-2 
sehingga ketika memberi

penilaian pada siswa

tidak kaku.

2. Sekolah Dasar Negeri

Danaraja Banyumas

a. Menyediakan peralatan yang digunakan untuk pembelajaran melalui permainan outdoor dalam meningkatkan keterampilan gerak dasar lokomotor.

3. Siswa kelas II SD Negeri Danaraja Banyumas a. Dengan penerapan permainan outdoor siswa menjadi antusias dalam mengikuti pembelajaran. Hal ini berpengaruh besar terhadap kompetensi akademik, sosial, dan kepribadian siswa kelas II SD Negeri Danaraja Banyumas.

b. Pada saat pembelajaran, siswa diharapkan selalu memperhatikan penjelasan dari guru. 


\section{DAFTAR PUSTAKA}

Ancok, D. (2002). Outbond Management Training. Yogyakarta: UII Press.

Departement of Education WA. (1013). Fundamental Movement Skills: Book 1 Learning, Teaching and Assessment. Western Australia: Departement of Education WA.

Hidayatullah, M. F. (2006). Mendidik anak dengan Bermain. Surakarta: Universitas Sebelas Maret Surakarta.

Hurlock, Elizabeth B. (2007). Perkembangan anak. Jilid I. Terjemahan Meitasri Tjandrasa, Muslichah Zarkasih, dan Agus Dharma. Jakarta: Penerbit Erlangga.

Ismail, A. (2006). Education Games Menjadi Cerdas dan Ceria dengan Permainan Edukatif. Yogyakarta: Pilar Media.

Mucholid, A. dan Satyawan, B. (2009). Aktivitass Luar Kelas. Surakarta: Pendidikan Profesi Guru FKIP UNS.

Parsons, A. (2011). Outdoor Play and Development, Experiences Fostering Environmental Consciousness, and the Implications on Playground Design. Virginia: Virginia Polytechnic Institute and State University.

Rahyubi, H. (2012). Teori-teori Belajar dan Aplikasi Pembelajaran Motorik Cetakan I. Bandung :Nusa Media.

Samsudin. (2008). Pembelajaran Jasmani Olahraga dan Kesehatan SD/MI. Jakarta: Litera Perdana Media Goup.

Semiawan, C. (2008). Belajar dan Pembelajaran Prasekolah dan Sekolah Dasar cetakan III. Indonesia: PT Macanan Jaya Cemerlang.

Thompson, A. (2004). Developing Fundamental Movement Skill Teacher's Guide. Online: www.ccea.org.uk.

Tedjasaputra, M. S. (2001). Bermain, mainandan permainan. Jakarta: PT Gramedia Widiasarana Indonesia.

Vera, A. (2012). Metode Mengajar Anak di Luar Kelas (Outdoor Study). Jogjakarta: DIVA Press.

Wardani, I. G. A. K. (2001). Psikologi Belajar. Jakarta: Universitas Terbuka. 